\section{Monetary Policy Analysis in Models Without Money}

\section{Bennett T. McCallum}

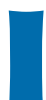
t has recently become common practiceindeed, virtually standard practice-for monetary policy analysis to be conducted in models that include no reference to any monetary aggregate. ${ }^{1}$ Although there have been a few protests, ${ }^{2}$ this general tendency is true of research conducted by both central bank and academic economists. ${ }^{3}$ The purpose of the present paper is to consider whether there is anything fundamentally misguided about this practice.

The paper begins by specifying a small prototype model that reflects today's standard approach and asking whether its adoption implies that monetary policy has little or nothing to do with money. The answer developed here is "no." Next it is argued that the prototype model excludes monetary aggregates only because of an assumption concerning the monetary transactions technology that seems unjustifiable in principle. We go on to consider whether elimination of this assumption, and the implied inclusion of a monetary aggregate, would be of quantitative importance in business cycle analysis. Again the apparent answer is "no."

The paper's third main topic involves indeterminacy issues that have been prominent in recent discussions of models and interest-rate policy rules of the type under consideration. Here it is argued that the undesirability of basing policy on forecasts of future inflation rates has been overstated in the theoretical literature, which has emphasized nonfundamental solutions that may be irrelevant empirically. As a related matter, the paper takes up the type of indeterminacy implied by a rule that does not respect the Taylor principle (i.e., that interest rates should be made to increase by more than point-for-point with inflation). It is argued that the nature of the problem in this case is different and

Bennett T. McCallum is the H.J. Heinz professor of economics at Carnegie Mellon University, a research associate of the National Bureau of Economic Research, and a research advisor at the Federal Reserve Bank of Richmond. The author is indebted to Marvin Goodfriend, Douglas Laxton, John Leahy, Allan Meltzer, Edward Nelson, and Alex Wolman for helpful comments. of genuine importance. Finally, it is noted that although these answers suggest that policy analysis in models without money is not fundamentally misguided, they do not imply that conducting policy in this manner is necessarily a desirable strategy.

\section{ARE MODELS WITHOUT MONEY NON-MONETARY MODELS?}

Let us begin by writing down a simple schematic prototype model without money of the sort that has been popular recently. Here and in the rest of the paper we use $y_{t}$ to denote the logarithm of real output during period $t$ with $\bar{y}_{t}$ being the natural-rate (i.e., flexible price) value of $y_{t}$ so that $\tilde{y}_{t}=y_{t}-\bar{y}_{t}$ is the output gap. Also $p_{t}$ is the log of the price level so that $\Delta p_{t}$ is the inflation rate, while $g_{t}$ represents the log of real government purchases and $R_{t}$ is the short-term nominal interest rate that the central bank uses as its instrument. Then the prototype model is:

(1)

$$
\begin{gathered}
y_{t}=b_{o}+b_{1}\left(R_{t}-E_{t} \Delta p_{t+1}\right)+E_{t} y_{t+1}+b_{2}\left(g_{t}-E_{t} g_{t+1}\right)+v_{t} \\
b_{1}<0, b_{2}>0
\end{gathered}
$$

$$
\begin{gathered}
R_{t}=\mu_{0}+E_{t} \Delta p_{t+1}+\mu_{1}\left(E_{t} \Delta p_{t+j}-\pi^{*}\right)+\mu_{2}\left(y_{t}-\bar{y}_{t}\right)+e_{t} . \\
\mu_{1}, \mu_{2}>0
\end{gathered}
$$

Here, equation (1) represents a forward-looking expectational IS function of the type that can be justified by dynamic optimization analysis, as explained by Kerr and King (1996), McCallum and Nelson (1999b), Woodford (1995, 1999), and many others. The stochastic disturbance $v_{t}$ represents the effects of taste shocks and is assumed to be exogenous, as are the "cost push" and policy shocks $u_{t}$ and $e_{t}$. Relation (2) is a price adjustment specifica-

\footnotetext{
1 For some prominent examples, see Clarida, Gali, and Gertler (1999), Rotemberg and Woodford (1997), and most of the papers in Taylor (1999).

2 For example, Meltzer (1999) and Nelson (2000).

3 The similarity of research strategies being used by central bank and academic economists can be seen by perusal of Taylor (1999) and the June 1999 issue of the Journal of Monetary Economics, which include papers from two major conferences on the topic of monetary policy rules.
} 
tion of the Calvo-Rotemberg type, which is the most nearly standard of those currently in use. ${ }^{4}$ For present purposes it will suffice to treat $\bar{y}_{t}$ as exogenous, as is usually done in small models, although Casares and McCallum (2000) show that it is not too difficult to endogenize investment and therefore $\bar{y}_{t} \cdot{ }^{5}$

Finally, equation (3) represents a policy rule of the Taylor (1993) type, which has the effect of adjusting upward the real interest rate $R_{t}-E_{t} \Delta p_{t+1}$ when current or expected inflation (depending on the value of $j$ ) exceeds its target value $\pi^{*}$ and/or the output gap is positive. For best performance the central bank will choose the parameter $\mu_{0}$ to equal $\bar{r}$, the long-run average real rate of interest, which in turn will equal $-b_{0} / b_{1}$, presuming that $E\left(g_{t}-E_{t} g_{t+1}\right)$ $=0$ (i.e., that we are abstracting from growth in $\bar{y}_{t}$ and $\left.g_{t}\right)$. Often an additional term in $R_{t-1}$ is included in the policy rule to represent interest rate smoothing.

Clearly, the system given by equations (1) through (3) includes no monetary aggregates. Yet it is complete, in the sense that the three relations govern time paths for the three endogenous variables, $y_{t}, \Delta p_{t}$, and $R_{t}$. It would be possible to add to the system a (base) money demand relation such as

(4) $\log M_{t}-p_{t}=c_{0}+c_{1} y_{1}+c_{2} R_{t}+\eta_{t}, \quad c_{1}>0, c_{2}<0$

but the latter would be superfluous, in the sense that it would not affect the behavior of $y_{t}, \Delta p_{t}$, or $R_{t} \cdot{ }^{6}$ Its only function would be to specify the amount of base money that is needed to implement the policy rule (3). Thus policy analysis involving $y_{t}, \bar{y}_{t}, \Delta p_{t}$, and $R_{t}$ can be carried out without even specifying a money demand function such as equation (4) or collecting measurements on the stock of money, $M_{t}$.

Nevertheless, it would be wrong to view this system without any monetary aggregate, equations (1) through (3), as representing a non-monetary model. For the central bank's control over the oneperiod nominal interest rate ultimately stems from its ability to control the quantity of base money in existence. If some entity other than the central bank could exogenously manipulate the path of $M_{t}$, then (4), (1), and (2) would determine paths for $y_{t}, \Delta p_{t}$, and $R_{t}$ with (3) being overruled.

Of course, the preceding statement presumes institutional arrangements much like those in existence today, in which it is appropriate to assume that the central bank has (monopoly) control over the issue of base money. Some writers, such as Friedman (1999), have suggested that technological progress in the payments and information process- ing industries may critically alter this situation in coming years and leave central banks with no control over the short-term interest rates that matter for macroeconomic purposes. Most of the Summer 2000 special issue of International Finance is devoted to a discussion of that possibility. In my opinion, Goodhart (2000) is correct to argue that, because central banks can be supported by governmental powers of regulation and taxation, they are unlikely to lose their control over interest rates in the foreseeable future.

In any event, there is an additional way to express the basic point at issue. This is to ask whether, according to the model (1) through (3), inflation is viewed as a non-monetary phenomenon, governed by the Phillips curve relationship (equation (2)). It is my contention that such a suggestion would be unjustified. Specifically, the primary issue in this regard is what controls the long-run average rate of inflation. And in the prototype model, that rate is controlled entirely by the central bank-the monetary authority. For this argument let us assume that the long run average value of $\tilde{y}_{t}$ is zero, i.e., that $E\left(y_{t}-\bar{y}_{t}\right)=0$ as is implied by the strict version of the natural rate hypothesis. ${ }^{7}$ Then from equation (1) we have that, in the absence of growth, $E\left(R_{t}-\Delta p_{t+1}\right)=-b_{0} / b_{1}$ so equation (3) implies that

$$
-b_{0} / b_{1}=\mu_{0}+\mu_{1}\left(E \Delta p_{t+j}-\pi^{*}\right)+\alpha E \tilde{y}_{t} .
$$

Thus it follows that, with $\mathrm{E} \tilde{y}=0$,

$$
E \Delta p_{t}=\pi^{*}-\left(\left(b_{0} / b_{1}\right)+\mu_{0}\right)\left(1 / \mu_{1}\right) \text {. }
$$

Consequently, if the central bank sets $\mu_{0}$ equal to the average real interest rate, $-b_{0} / b_{1}$, as a sensible central bank would, then the average inflation rate will equal the central bank's chosen target value $\pi^{*}$. And if it errs by, for instance, $\varepsilon$ in setting $\mu_{0}$, the average inflation rate will differ from $\pi^{*}$ by $\varepsilon / \mu_{1}$, which becomes smaller as the policy rule's response to

\footnotetext{
4 There has recently been much controversy over the adequacy of the Calvo-Rotemberg specification since it itself supplies no persistence to the inflation rate; see Estrella and Fuhrer (2000) and Gali and Gertler (1999) for an introduction to the controversy.

5 This, of course, requires that equation (1) be replaced by a set of equations representing an "expectational IS sector."

6 Here $M_{t}$ is the nominal money stock. For present purposes we can think of it both as base money and as the relevant monetary aggregate that facilitates transactions.

7 This version is due to Lucas (1972). For more discussion, see McCallum and Nelson (1999a).
} 
discrepancies of inflation from its target becomes stronger. Basically, then, the average inflation rate is determined by central bank behavior. Parameters $\alpha$ and $\beta$ from the Phillips relationship (equation (2)) play no role.

There is an apparent problem with the foregoing demonstration, namely, that the Calvo-Rotemberg relation (2) becomes $E \pi=\beta E \pi+\alpha E \tilde{y}$ in the steady state, which implies (with $\beta<1$ ) that $E \tilde{y}>0$. The latter condition, however, violates the natural rate hypothesis, in contradiction with the assumption made above. In my opinion this points to a flaw in the usual formulation of the Calvo-Rotemberg model. ${ }^{8}$ Instead of a derivation pertaining to the costs or impossibility of changing prices in relation to the previous period's level, a rational version of the model would be concerned with changes relative to the previous period's level plus the average one-period inflation rate, as in the version of the model used by Ireland (2000). In that case, there would be no problem with the foregoing argument. Furthermore, although the inflation rate would depend upon Phillips curve parameters if one were to insist on retaining (2), the same would be true if the central bank were to control the monetary base as its instrument variable, assuming that the policy feedback rule was one that involved both $\pi-\pi^{*}$ and $\tilde{y}$ as objectives.

\section{IS NEGLECT OF MONEY QUANTITATIVELY IMPORTANT?}

The objective of this section is to look into the theoretical foundations for the prototype model (equations (1) through (3)) and follow up with a quantitative analysis. ${ }^{9}$ Actually, the focus will be only on equations (1) and (4) because the policy rule (3) is simply being taken as an object of investigation, whereas issues relating to the price adjustment specification (2) are quite distinct and beyond the scope of this paper. ${ }^{10}$ Thus we begin by reviewing the optimizing rationale for (1) and (4), which is reasonably familiar from the references mentioned on $\mathrm{p} .1$.

For simplicity, suppose that capital is treated as a constant, $k$. Then a typical household, which supplies inelastically one unit of labor per period, seeks at time $t=1$ to maximize

$$
\sum_{t=1}^{\infty} \beta^{t-1} u\left(c_{t}, \zeta_{t}\right)
$$

where $c_{t}$ represents Dixit-Stiglitz consumption bundles and $\zeta_{t}$ is a stochastic shock to preferences. The household's budget constraints for $t=1,2, \ldots$ are
(7)

$$
\begin{aligned}
& Y_{t}^{A}\left(P_{t} / P_{t}^{A}\right)^{1-\theta}-t x_{t}-w_{t}\left(n_{t}-1\right)= \\
& c_{t}+m_{t}-\left(1+\pi_{t}\right)^{-1} m_{t-1}+\left(1+r_{t}\right)^{-1} b_{t+1}-b_{t}+\psi\left(c_{t}, m_{t}\right) .
\end{aligned}
$$

Here $Y_{t}^{A}$ is aggregate per-household demand while $P_{t} / P_{t}^{A}$ is the price of the household's specialized output relative to the implied Dixit-Stiglitz price index of goods in general. Also, $t x_{t}$ is lump-sum taxes paid (net of transfers); $n_{t}$ is labor employed in production so with a real wage of $w_{t}$ we have $w_{t}\left(n_{t}-1\right)$ as the household's net payment to hired labor; $m_{t}$ is real money balances held at the end of period $t$; $\pi_{t}=\left(P_{t}^{A} / P_{t-1}{ }^{A}\right)-1$ is the inflation rate; and $b_{t+1}$ is the number of real bonds purchased, at a real price of $1 /\left(1+r_{t}\right)$, during $t$. Finally, $\psi\left(c_{t}, m_{t}\right)$ represents the resources used in conducting transactions (i.e., in shopping for the precise bundle of consumption goods that the household chooses). The household produces output subject to the production function $Y_{t}=f\left(A_{t} n_{t}, k\right)$, where $A_{t}$ is a technology shock, and its amount produced is equal to the quantity demanded:

$$
f\left(A_{t} n_{t}, k\right)=Y_{t}^{A}\left(P_{t} / P_{t}^{A}\right)^{-\theta}
$$

As is common, we assume $0<\beta<1, \theta>1$, and that $f$ is well behaved. The transaction technology is such that $\psi_{1}\left(c_{t}, m_{t}\right)>0$ and $\psi_{2}\left(c_{t}, m_{t}\right) \leq 0$.

In this setup the household's first order conditions are as follows for $t=1,2, \ldots$, with $\lambda_{t}$ and $\xi_{t}$ being the Lagrange multipliers on (7) and (8):

$$
\lambda_{t} Y_{t}^{A}(1-\theta) P_{t}^{-\theta} /\left(P_{t}^{A}\right)^{1-\theta}+\xi_{t} Y_{t}^{A} \theta P_{t}^{-(\theta+1)} /\left(P_{t}^{A}\right)^{-\theta}=0 .
$$

Thus equations (7) through (13) determine the household's choices of $c_{t}, m_{t}, n_{t}, b_{t+1}, P_{t}, \lambda_{t}$, and $\xi_{t}$

\footnotetext{
8 My own preferred price adjustment scheme is the "P-bar" model used by McCallum and Nelson (1999a).

9 The issue at hand has been addressed previously by Ireland (2001), McCallum (2000), and Nelson (2000). Here we take a somewhat different approach.

${ }^{10}$ Details concerning price adjustment are, in other words, basically unrelated to this paper's central concern.
} 
in response to exogenous, market-given, or government-specified values of $w_{t}, A_{t}, \pi_{t}, r_{t}, Y_{t}^{A}$, and $P_{t}^{A}$.

For general equilibrium, the additional relations are

$$
\begin{gathered}
n_{t}=1 \\
m_{t}=M_{t} / P_{t} \\
G_{t}-t x_{t}=m_{t}-\left(1+\pi_{t}\right)^{-1} m_{t-1}+\left(1+r_{t}\right)^{-1} b_{t+1}-b_{t} \\
\pi_{t}=\left(P_{t}^{A} / P_{t-1}^{A}\right)-1 .
\end{gathered}
$$

Then with $M_{t}, G_{t}$, and $t x_{t}$ given exogenously by policy, and assuming symmetry among households so that $P_{t}=P_{t}^{A}$ and $Y_{t}^{A}=f\left(A_{t} n_{t}, k\right)$, the system also determines endogenously the values of $w_{t}, r_{t}, P_{t}$, and $\pi_{t}$.

This last statement presumes that the monetary authority - part of the "government" - exogenously controls $M_{t}$. But if we introduce the nominal rate of interest $R_{t}$ defined by the Fisher identity,

$$
1+R_{t}=\left(1+r_{t}\right) E_{t}\left(1+\pi_{t+1}\right),
$$

then we could reverse the roles of $R_{t}$ and $M_{t}$, making the latter endogenous and the former policygoverned.

Also, we could introduce stickiness of nominal product prices. Suppose we did so by adding another relation such as

$$
\Delta p_{t}=\beta E_{t} \Delta p_{t+1}+\alpha\left(y_{t}-\bar{y}_{t}\right),
$$

which is the same as (2). Here $p_{t}=\log P_{t}$ and again $y_{t}=\log Y_{t}$ with $\bar{y}_{t}$ being the flexible-price value of $y_{t}$ that would be produced if there were no price stickiness, that is, $\bar{y}_{t}=f\left(A_{t} 1, k\right)$. The introduction of (19) requires, in order to prevent overdetermination, that one of the previously prevailing conditions be eliminated. The simplest option, and in my opinion the most realistic, is to eliminate the condition for labor market equilibrium-equation (14). Then labor and output will both be demand determined.

The crucial issue, in the present context, is whether a relation such as (1) - with no money term involved - can be justified by our optimizing equilibrium analysis. In that regard we solve (9) for $\lambda_{t}$ and substitute into (12):

(20) $\frac{u_{1}\left(c_{t}, \zeta_{t}\right)}{\left[1+\psi_{1}\left(c_{t}, m_{t}\right)\right]}=\left(1+r_{t}\right) \beta E_{t}\left\{\frac{u_{1}\left(c_{t+1}, \zeta_{t+1}\right)}{\left[1+\psi_{1}\left(c_{t+1}, m_{t+1}\right)\right]}\right\}$.

Now, if $\psi\left(c_{t}, m_{t}\right)$ were separable, so that $\psi_{1}$ did not involve $m$, equation (20) would include only $c_{t}, c_{t+1}$, and $r_{t}$ (plus shock terms). It would then be possible to write a log-linearized approximation of the form

$$
\log c_{t}=b_{0}{ }^{\prime}+E_{t} \log c_{t+1}+b_{1}{ }^{\prime} r_{t}+v_{t}{ }^{\prime},
$$

where $v_{t}^{\prime}$ represents $\zeta_{t}-E_{t} \zeta_{t+1}$. The latter is a familiar consumption Euler equation, although it differs from the most common version by incorporating the influences of the transactions term $\psi\left(c_{t}, m_{t}\right)$. Continuing, a log-linearized approximation to the overall resource constraint for the economy at hand, with constant capital, is

$$
\log Y_{t}=(c / Y) \log c_{t}+(G / Y) \log G_{t},
$$

where $(c / Y)$ and $(G / Y)$ are steady-state shares. Substitution of (21) into (22) then yields

(23) $\log Y_{t}+E_{t} \log Y_{t+1}+b_{0}+b_{1} r_{t}+b_{2}\left(g_{t}-E_{t} g_{t+1}\right)+v_{t}$,

where $g_{t}=\log G_{t}$. This relation is of the form of equation (1), so the latter can be justified. But this justification relies upon the assumption that $\psi\left(c_{t}, m_{t}\right)$ is separable, and in fact that seems implausible. Much more likely, I would think, would be a $\psi\left(c_{t}, m_{t}\right)$ function that made the cross partial derivative negative, so that the marginal benefit of holding money-i.e., the reduction in transaction costsincreases with the volume of consumption spending.

In McCallum (2000a), I proposed the following as a first-guess specification for $\psi$ :

$$
\psi\left(c_{t}, m_{t}\right)=c_{t} a_{1}\left(c_{t} / m_{t}\right)^{a_{2}} . \quad a_{1}, a_{2}>0
$$

Furthermore, it is shown there that the resulting implication for (23) is that it should then include an additional term, namely,

$$
\begin{aligned}
& b_{3}\left(\log m_{t}-E_{t} \log m_{t+1}\right) \equiv \\
& (c / Y) \phi(\phi+\sigma)^{-1}\left(\log m_{t}-E_{t} \log m_{t+1}\right),
\end{aligned}
$$

with $\phi=a_{1}\left(1+a_{2}\right) a_{2}(\mathrm{clm})^{a_{2}}$, where $\sigma$ is the inverse of the intertemporal elasticity of substitution in consumption. This equation can then be written

$$
\begin{aligned}
& \text { (1') } y_{t}=b_{0}+b_{1}\left(R_{t}-E_{t} \Delta p_{t+1}\right)+E_{t} y_{t+1} \\
& +b_{2}\left(g_{t}-E_{t} g_{t+1}\right)+b_{3}\left(\log m_{t}-E_{t} \log m_{t+1}\right)+v_{t} .
\end{aligned}
$$

Numerical values for $a_{1}$ and $a_{2}$ will be considered shortly.

Another implication of the assumed specification (24) concerns the implied demand for money 
function. We see that (11) and (12), together with the Fisher identity, imply

$$
1+\psi_{1}\left(c_{t}, m_{t}\right)=\left(1+R_{t}\right)^{-1}
$$

or, approximately,

$$
-\psi_{1}\left(c_{t}, m_{t}\right)=R_{t}
$$

But with (24) this gives

$$
a_{1} a_{2}\left(c_{t} / m_{t}\right)^{1+a_{2}}=R_{t}
$$

or

$$
\begin{aligned}
& \log m_{t}= \\
& {\left[\left(\log a_{1} a_{2}\right) /\left(1+a_{2}\right)\right]+\log c_{t}-\left(1 /\left(1+a_{2}\right)\right) \log R_{t} .}
\end{aligned}
$$

Thus we have a money demand function with a constant elasticity with respect to $R_{t}$ of $-1 /\left(1+a_{2}\right)$ and an elasticity with respect to spending of 1.0 . This relation can now be added to our model, which becomes (2), (3), (29), and (1'); these govern the behavior of $y_{t}, \Delta p_{t}, R_{t}$, and $m_{t}$.

Furthermore, equation (29) (or (28)) is useful in assigning values to $a_{1}$ and $a_{2}$, i.e., in calibration. Let us begin by assuming a money demand elasticity of -0.2 ; that choice implies $a_{2}=4$. Also, for a quarterly model let us assume an average interest rate of 0.0125 (i.e., 5 percent per year) and an average $\mathrm{c} / \mathrm{m}$ ratio of 1.25 . Then (28) becomes $a_{1}(4)(1.25)^{5}=$ 0.0125 , implying $a_{1}=0.00102$. Then the crucial parameter $\phi$ becomes

$$
\phi=0.00102 \text { (5) (4) }(1.25)^{4}=0.0204(2.44)=0.0498 \text {, }
$$

and the slope coefficient $b_{3}$ in (25) is, assuming $\sigma=2$ and $(c / Y)=0.7$,

$$
\text { (31) }(c / Y) \phi(\phi+\sigma)^{-1}=(0.7)(0.0498) /(2.0498)=0.017 \text {. }
$$

The remainder of our calibration is more standard: $\beta=0.99, \alpha=0.05, \theta=5$, and the policy rule parameters $\mu_{1}=0.5, \mu_{2}=0.1, \mu_{3}=0.8$. The latter value refers to an extension of the Taylor rule to reflect interest rate smoothing:

(3')

$$
\begin{aligned}
& R_{t}= \\
& \left(1-\mu_{3}\right)\left[\mu_{0}+E_{t} \Delta p_{t+1}+\mu_{1}\left(E_{t} \Delta p_{t+1}-\pi^{*}\right)+\mu_{2} E_{t-1} \tilde{y}_{t}\right] \\
& +\mu_{3} R_{t+1}+e_{t} .
\end{aligned}
$$

Note that in the latter we have used $E_{t} \Delta p_{t+1}$, setting $j=1$ in (3). Also, $v_{t}$ is white noise and we have generated $\bar{y}_{t}$ by the process $\bar{y}_{t}=0.95 \bar{y}_{t-1}+a_{t}$, with $a_{t}$ white noise. Finally, we have made one more modification to the model at hand, in an attempt to have fairly realistic specifications for parts of the system not under scrutiny. This modification is to replace the price adjustment relation (2) with the following:

$$
\left(2^{\prime}\right) \quad \Delta p_{t}=0.5 \beta\left[E_{t} \Delta p_{t+1}+\Delta p_{t-1}\right]+\alpha \tilde{y}_{t}+e_{t} .
$$

Here we have included the $\Delta p_{t-1}$ term to reflect inflation inertia that appears to exist in many developed economies.

The model at hand consists, then, of relations $\left(1^{\prime}\right),\left(2^{\prime}\right),\left(3^{\prime}\right)$, and $(4)$, specified to approximate (28). ${ }^{11}$ The object is to see if the inclusion of the term (25) in ( $\left.1^{\prime}\right)$ substantially affects the behavior of $\Delta p_{t}$ and $y_{t}$-i.e., whether theoretically incorrect exclusion of money from the system is of quantitative importance. For this purpose, impulse response functions are very well suited. As a tool for comparing a model with actual economic behavior, impulse response functions are of dubious value because of the need for shock identification. But they are more sensitive than autocorrelation functions to model specification, so are highly appropriate for the purpose at hand. Consequently, Figure 1 shows impulse response functions for $y_{t}, \Delta p_{t}$, and $R_{t}$ for unit shocks to $v_{t}, e_{t}$, and $a_{t}$. In the top half of the figure we have included the $m_{t}$ terms in $\left(1^{\prime}\right)$, whereas in the bottom half they are excluded. It is obvious that there is no appreciable difference.

That there would be an appreciable difference, if the coefficient in (25) were larger, is illustrated in Figure 2. There we take the coefficient to be 0.2 , holding everything else (including $c_{2}$ ) unchanged. Now the output and inflation responses are noticeably different, especially in response to a monetary policy shock.

In addition, as a quick robustness check we assume that the money demand elasticity is -0.1 , rather than -0.2 , implying that $a_{2}=9$ instead of 4 . This change yields $b_{3}=0.033$ and $c_{2}=-8$. The results, shown in the bottom half of Figure 2, are scarcely different from those in Figure 1. Finally, we note that decreasing rather than increasing $a_{2}$ (making money demand more elastic) would make the effect even smaller than in our initial case.

Our investigation suggests, then, that although it is theoretically incorrect to specify a model without money, the magnitude of the error thereby

\footnotetext{
11 Thus $c_{2}$ in (4) equals $-1 /\left(R\left(1+a_{2}\right)\right)$, which equals -16 when $a_{2}=4$.
} 


\section{Figure 1}
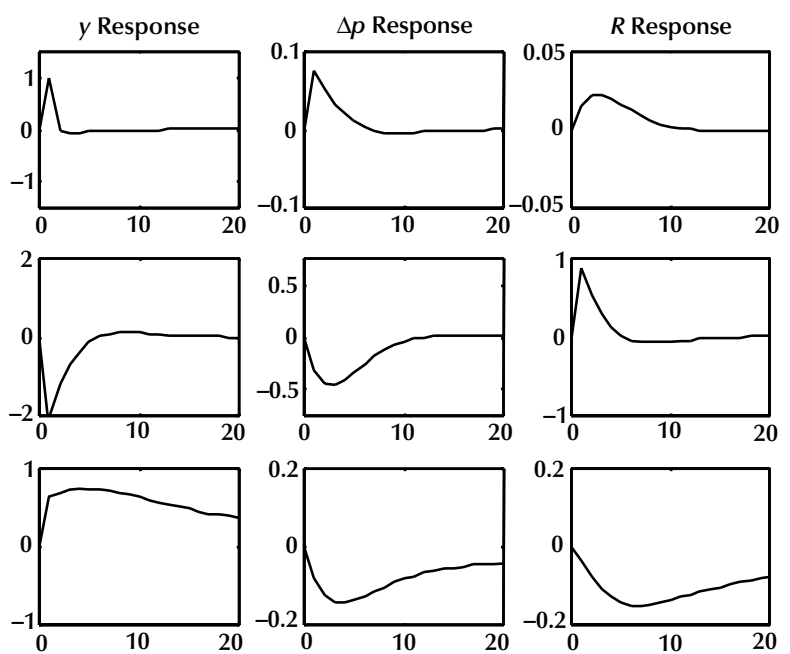

NOTE: Unit shocks to IS (top), policy rule (mid), and tech with money $\left(b_{3}=0.017\right)$.
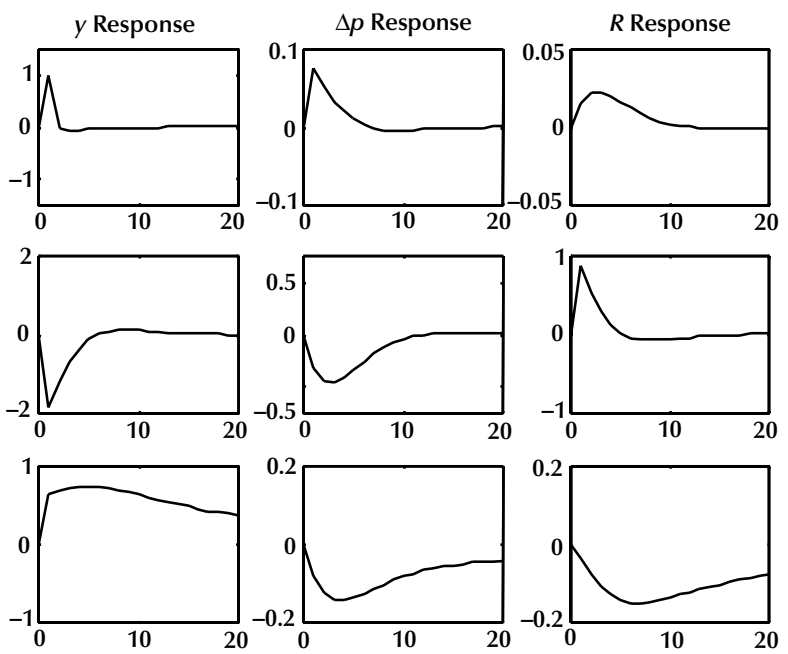

NOTE: Unit shocks to IS (top), policy rule (mid), and tech without money $\left(b_{3}=0.0\right)$.

introduced is extremely small. This finding is basically consistent with those of Ireland (2001), who finds that econometric estimates of a parameter analogous to $b_{3}$ are insignificantly different from zero. ${ }^{12}$

\section{ARE RATIONAL-EXPECTATION INDETERMINACIES IMPORTANT?}

Models without money are typically ones in which an interest rate serves as the policy instrument that is adjusted in response to macroeconomic

\section{Figure 2}
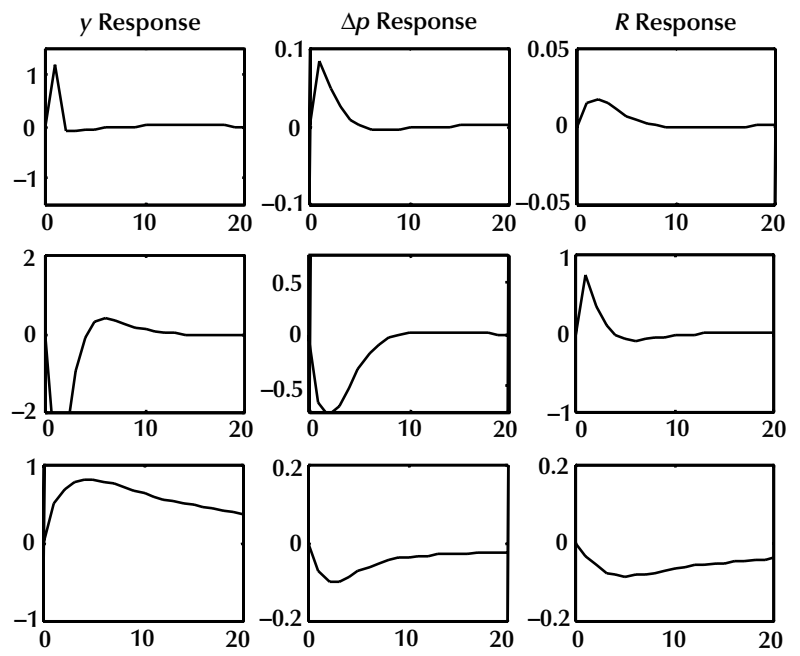

NOTE: Unit shocks to IS (top), policy rule (mid), and tech with money $\left(b_{3}=0.2\right)$.
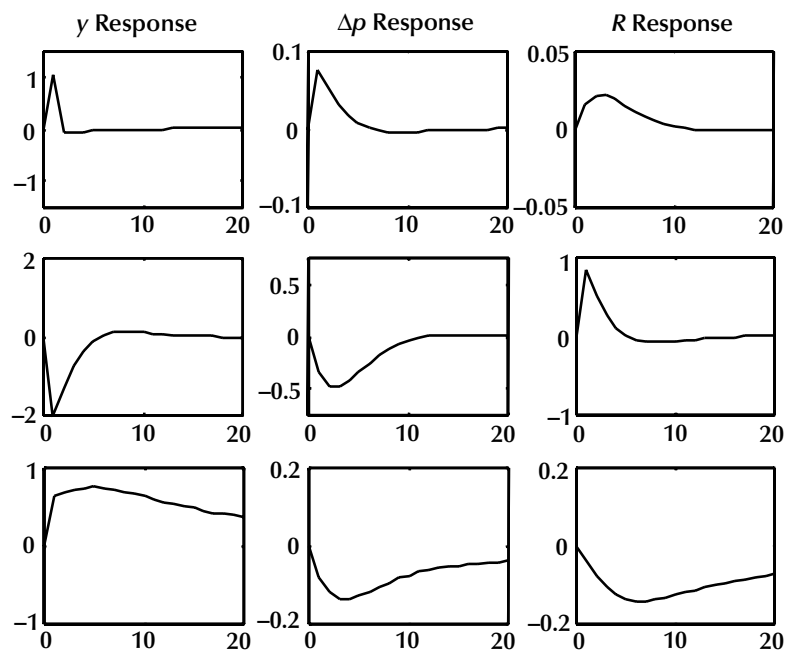

NOTE: Unit shocks to IS (top), policy rule (mid), and tech with money $\left(a_{2}=9\right)$.

conditions, prominently including inflation. Central bankers and practical analysts stress the need to move preemptively, i.e., to adjust the policy stance when inflation forecasts get out of line without waiting for realized inflation to depart strongly from its target path (see, e.g., Goodfriend, 1997, and Svensson, 1997). There is, however, a line of theoretical analysis that warns of the danger of

\footnotetext{
12 Ireland (2001) shows that, for his preferred rationalization of sticky prices, a term involving $m_{t}$ also appears in the price adjustment relation.
} 
"indeterminacy" if central banks' $R_{t}$ policy rules respond too strongly to rational forecasts of future inflation, even if the same responses to current inflation would not be problematic. This argument was first developed by Woodford (1994) and has subsequently been promoted, or discussed with apparent approval, by Bernanke and Woodford (1997); Kerr and King (1996); Clarida, Gali, and Gertler (1997); Svensson (1997); Christiano and Gust (1999); Carlstrom and Fuerst (2000); Isard, Laxton, and Eliasson (1999); and Bullard and Mitra (2000). Its main message, that variants of inflationforecast targeting are likely to generate undesirable outcomes, seems rather surprising in light of the descriptions of actual policy procedures used by the Bank of England, Reserve Bank of New Zealand, and Bank of Canada. ${ }^{13}$ Note in this regard that for very large values of $\mu_{1}$, in a policy rule like (3), the implied policy is virtually the same as exact targeting of an expected inflation rate, as promoted by Svensson (1997) and others. Thus the argument seems to deserve scrutiny. The present section extends and elaborates on an alternative argument briefly outlined in McCallum (1999, pp. 634-35), which suggests that the danger identified by the line of analysis in question represents a theoretical curiosity that is probably not of practical relevance.

Let us begin the discussion by noting the way in which the term "indeterminacy" is used in this body of literature. The term first became prominent in monetary economics from a series of writings by Patinkin - beginning with (1949) and culminating with (1961) and (1965) - that grew out of observations made by Lange (1942) about a putative logical inconsistency in classical monetary theory. Some of Patinkin's conclusions were disputed in a notable book by Gurley and Shaw (1960), and the resulting controversy was prominently reviewed in an influential survey article by Johnson (1962). In all of this earlier literature, it must be noted, the form of indeterminacy under discussion was "price level indeterminacy" such that the models in question fail to determine the value of any nominal variable, including the money supply. That type of failure occurs basically because of postulated policy behavior that is entirely devoid of any nominal anchori.e., there is no concern by the central bank for nominal variables. ${ }^{14}$ Since rational private households and firms care only about real variables, according to standard neoclassical analysis, the absence of any "money illusion" by them and by the central bank must imply that no agent (in the model) has any concern for any nominal variable. Thus there is in effect no nominal variable appearing anywhere in the model, so naturally it cannot determine the value of such variables.

Arguably, a dynamized, rational expectations version of this type of price-level indeterminacy, in the context of an interest rate policy rule, was developed by Sargent and Wallace (1975) and exposited in Sargent's influential textbook (1979, pp. 362-63). But of course this type of indeterminacy disappears if the central bank provides a nominal anchor, as was recognized by Parkin (1978) and McCallum (1981), even in the presence of rational expectations and the complete absence of private money illusion.

The type of indeterminacy under discussion in the current literature cited at the beginning of this section is very different. Instead of a failure to determine any nominal variable (without any implied problematic behavior for real variables), the recent Woodford-warning 15 literature is concerned with a multiplicity of stable equilibria in terms of real variables. ${ }^{16}$ This type of aberrational behavior stems not from the absence of any nominal anchor (a static concept) but from the (essentially dynamic) fact that various paths of real money balances can be consistent with rational expectations under some circumstances. In order to avoid possible semantic confusions, McCallum (1986) proposed that different terms be used for the two types of aberrational behavior - nominal indeterminacy and solution multiplicity, respectively. ${ }^{17}$ It is necessary to report, however, that this proposal has not met with widespread acceptance.

Of what importance is the distinction emphasized in the last paragraph? As an example of the sort of confusion that can arise if the distinction is not recognized, let us refer to the analysis of "price level indeterminacy" under an interest rate rule in the famous JPE paper by Sargent and Wallace (1975) mentioned above. It has long been my own belief

\footnotetext{
${ }^{13}$ See, for example, descriptions by King (1999), Archer (2000), and Freedman (2000).

${ }^{14}$ See Patinkin (1965, p. 309).

${ }^{15}$ This term is due to Lars Svensson.

${ }^{16}$ It is dynamically stable equilibria that are relevant because explosive paths of real variables are normally ruled out by transversality conditions that show them to be suboptimal for individual private agents.

${ }^{17}$ The adjective "nominal" was omitted from my original proposal, but seems clearly to be desirable.
} 
that the Sargent-Wallace (1975) paper was concerned with nominal indeterminacy - see McCallum (1981, 1986). Woodford (1999, Chap. 2), by contrast, interprets this Sargent and Wallace discussion as pertaining to solution multiplicity. My position is strengthened by the fact that the only substantive reference cited by Sargent and Wallace is Olivera (1970), which is clearly concerned with nominal indeterminacy. But there is something to be said for Woodford's position: under his interpretation the Sargent-Wallace result is valid, whereas under mine it is invalid (see McCallum, 1986, p. 148). Possibly Sargent and Wallace were undecided in their own thinking about which of the two concepts was being considered. In any event, their paper and the writings that have followed illustrate clearly the importance of making the distinction.

Let us now consider the substance of the Woodford warning of multiple solutions when policy is based on rational forecasts of future inflation. ${ }^{18}$ It can be illustrated in a model such as our prototype (1) through (3) presented above. For convenience, let us rewrite the model here, omitting for simplicity the $g_{t}$ term and treating $\bar{y}_{t}$ as a constant normalized to zero. Also, let us ignore constant terms that are tedious and for present purposes uninteresting. Finally, let us suppose that $E_{t} \Delta p_{t+1}$ is the inflation-forecast variable to which the policy rule pertains. Then the system can be written as

$$
\begin{gathered}
y_{t}=b_{1}\left(R_{t}-E_{t} \Delta p_{t+1}\right)+E_{t} y_{t+1}+v_{t} \\
\Delta p_{t}=\beta E_{t} \Delta p_{t+1}+\alpha y_{t} \\
R_{t}=\left(1+\mu_{1}\right) E_{t} \Delta p_{t+1}+\mu_{2} y_{t}+e_{t} .
\end{gathered}
$$

Here we suppose that $u_{t}$ is absent from (2) while $e_{t}$ in (3) is white noise, but that $v_{t}$ in (1) is generated by a first-order autoregressive process-denoted AR(1) - as follows:

$$
v_{t}=\rho_{1} v_{t-1}+\varepsilon_{1 t} .
$$

Here $\varepsilon_{1 t}$ is white noise and the AR parameter satisfies $\left|\rho_{1}\right|<1.19$

In this model the unique minimum-statevariable (MSV) rational expectations solution is of the form 20

$$
\begin{gathered}
y_{t}=\phi_{11} v_{t}+\phi_{12} e_{t} \\
\Delta p_{t}=\phi_{21} v_{t}+\phi_{22} e_{t} .
\end{gathered}
$$

Then we have $E_{t} y_{t+1}=\phi_{11} \rho_{1} v_{t}$ and $E_{t} \Delta p_{t+1}=\phi_{21} \rho_{1} v_{t}$; consequently, standard undetermined coefficient calculations yield

$$
\begin{gathered}
\phi_{11}=1 /\left[1-\rho_{1}-b_{1} \mu_{2}-\left(\alpha b_{1} \mu_{1} \rho_{1}\right) /\left(1-\beta \rho_{1}\right)\right] \\
\phi_{12}=b_{1} /\left(1-b_{1} \mu_{2}\right) \\
\phi_{21}=\alpha /\left[\left(1-\beta \rho_{1}\right)\left(1-\rho_{1}-b_{1} \mu_{2}\right)-\alpha b_{1} \mu_{1} \rho_{1}\right] \\
\phi_{22}=\alpha b_{1} /\left(1-b_{1} \mu_{2}\right) .
\end{gathered}
$$

It is easy to verify that $\phi_{11}>0, \phi_{12}<0, \phi_{21}>0$, and $\phi_{22}<0$-i.e., that both $y_{t}$ and $\Delta p_{t}$ respond positively to a demand shock and negatively to a random, policy-induced blip in $R_{t}$. Thus the MSV solution suggests that there is no problem with the inflationforecast targeting rule (34).

Suppose, however, that a researcher looks for non-MSV solutions of the form

$$
\begin{gathered}
y_{t}=\phi_{11} v_{t}+\phi_{12} e_{t}+\phi_{13} \Delta p_{t-1} \\
\Delta p_{t}=\phi_{21} v_{t}+\phi_{22} e_{t}+\phi_{23} \Delta p_{t-1},
\end{gathered}
$$

where the extraneous state variable $\Delta p_{t-1}$ is included. These expressions imply $E_{t} y_{t+1}=\phi_{11} \rho_{1} v_{t}+$ $\phi_{13}\left(\phi_{21} v_{t}+\phi_{22} e_{t}+\phi_{23} \Delta p_{t-1}\right)$ and $E_{t} \Delta p_{t+1}=\phi_{21} \rho_{1} v_{t}+$ $\phi_{23}\left(\phi_{21} v_{t}+\phi_{22} e_{t}+\phi_{23} \Delta p_{t-1}\right)$. Then undetermined coefficient reasoning implies that the values for the $\phi_{i j}$ are given by six relations analogous to (38) among which are

$$
\phi_{13}=b_{1} \mu_{1} \phi_{23}^{2}+b_{1} \mu_{2} \phi_{13}+\phi_{13} \phi_{23}
$$

and

$$
\phi_{23}=\beta \phi_{23}^{2}+\alpha \phi_{13} \text {. }
$$

From these $\phi_{13}$ can be solved out, yielding the cubic equation

$$
\phi_{23}=\beta \phi_{23}^{2}+\alpha b_{1} \mu_{1} \phi_{23}^{2} /\left(1-b_{1} \mu_{2}-\phi_{23}\right) .
$$

Inspection of the latter indicates that one solution

\footnotetext{
18 Note that I am not disputing the different point that central banks need to base policy on their own information and structural models, also discussed by Woodford (1994) and Bernanke and Woodford (1997).

${ }^{19}$ It will be observed that the current system is somewhat simpler than the one used in the third section of the paper ("Is the Neglect of Money Quantitatively Important?"). The reason is to have one in the current section that permits some analytical results to be obtained, so that more understanding of the numerical results will be possible. The basic results also pertain to more general models.

20 The MSV concept is discussed at length in McCallum (1999), where it is interpreted as the unique solution that includes no bubble or sunspot components. A solution procedure is there proposed that generates a unique solution by construction in a very wide class of linear RE models.
} 
is provided by $\phi_{23}=0$, which implies $\phi_{13}=0$. This, of course, gives the MSV solution obtained previously. But (43) is also satisfied by roots of the quadratic

$$
\beta \phi_{23}^{2}-\left[1+\beta+\alpha b_{1} \mu_{1}-b_{1} \mu_{2} \beta\right] \phi_{23}+\left(1-b_{1} \mu_{2}\right)=0
$$

i.e., by

$$
\phi_{23}=\frac{d \pm\left[d^{2}-4 \beta\left(1-b_{1} \mu_{2}\right)\right]^{0.5}}{2 \beta},
$$

where $d$ is the term in square brackets in (44). Therefore, for some values of the parameters $\alpha, \beta, b_{1}, \mu_{1}$, and $\mu_{2}$ there may be other real solutions in addition to the MSV solution. ${ }^{21}$

To keep matters relatively simple, let $\mu_{2}=0$ so that the policy rule responds only to expected inflation. Then $d$ becomes $1+\beta+\alpha b_{1} \mu_{1}$, and there will be two real roots to (44) if $\mu_{1}<0$ or $\mu_{1}>\mu_{1}^{c} \equiv$ $\left[2 \beta^{0.5}+1+\beta\right] /\left(-b_{1} \alpha\right)$. Furthermore, while one of the $\phi_{23}$ values in (44) will exceed 1.0 in absolute value when $\mu_{1}>\mu_{1}^{c}$, the other will not -it will be a (negative) stable root. Consequently, there will be no transversality condition to rule out that root's implied trajectory as a rational expectations (RE) equilibrium. Thus there is, for $\mu_{1}>\mu_{1}^{c}$, an infinite multiplicity of stable RE solutions indexed by the initial start-up value of $\Delta p_{t-1}$. In such cases, moreover, "sunspot" solutions are also possible in the sense of not being ruled out by the conditions of RE equilibria. ${ }^{22}$ This is the danger pointed out by the Woodford warning, and it is made more likely when values of $\mu_{2}$ exceed zero. ${ }^{23}$

I now wish to argue that the foregoing danger may not be of any practical significance, for it is entirely possible that non-MSV-i.e., bubble and sunspot-solutions are empirically irrelevant. ${ }^{24}$ That such is the case is a cogent and plausible hypothesis, which to my knowledge has not been convincingly contradicted by any empirical tests, despite the enormous amount of interest shown by researchers over the past 25 years. In support of this position, I will offer two infrequently-stated lines of argument.

The first line of argument, in favor of the proposition that only MSV solutions are of empirical relevance, concerns the nature and role of the RE hypothesis. No one, I would think, believes that the orthogonality conditions for RE literally obtain precisely in real world economies, any more than do the conditions for exact profit and utility maximization. The hypothesis is extremely fruitful and attractive nevertheless because it points to a pow- erful force, the desirability (for purposeful agents) of eliminating any systematic component of their expectational errors. And it keeps analysts from constructing models in which it is possible for agents to repeatedly commit the same type of expectational error, over and over again. But to suggest that the "expectation function," 25 which describes actual expectational behavior, can jump from one specification (e.g., the MSV form $\Delta p_{t+1}^{e}=\phi_{21} \rho_{1} v_{t}$ ) to another (e.g., the non-MSV form $\Delta p_{t+1}^{e}=\phi_{21} \rho_{1} v_{t}+$ $\phi_{23}\left[\phi_{21} v_{t}+\phi_{22} e_{t}+\phi_{23} \Delta p_{t-1}\right]$ with different $\phi_{i j}$ values) at any point of time - without any particular stimulus - seems downright whimsical. Much more plausible, I would contend, is the idea that such expectation functions are uniquely given at any point of time for any specified economy and policy regime. This does not imply, of course, that expectations themselves, e.g., $\Delta p_{t+j}^{e}$, cannot jump abruptly from one period to the next.

In this regard, the theoretical work of Evans (1986) and Evans and Honkapohja $(1999,2001)$ is in my opinion predominantly supportive of the hypothesis that the unique MSV solution is relevant for macroeconomic analysis. ${ }^{26}$ With respect to the model at hand, for example, it is shown by Bullard and Mitra (2000, Figure 3) that the MSV solutions are E-stable, and therefore learnable by a real-time least-squares learning procedure, for the cases with large $\mu_{1}$ and/or $\mu_{2}$ values. ${ }^{27}$ Bullard and Mitra do not analyze the E-stability/learnability properties of the non-MSV solutions, but very closely related cases have been analyzed by Evans (1986, pp. 150-53) and

21 An analysis is provided by Bullard and Mitra (2000, p. 26).

22 By a sunspot solution I mean one that includes random variables (of a martingale difference variety) that have no connection with other elements of the model.

23 See, e.g., Bullard and Mitra (2000).

24 At least, in macroeconomic contexts.

25 An expectations function is a formula relating an expectational variable, such as the period- $t$ expectation of $z_{t+j}$, denoted $z_{t}{ }_{t+j}$, to observable variables.

${ }^{26}$ Evans and Honkapohja themselves might not agree. In any event, their recent terminology differs from mine in that they use the term MSV to refer to solutions that in some cases obtain in addition to the one that is specified by my concept of the MSV procedure. (See Evans and Honkapohja, 1999, p. 488; 2001, Chaps. 8-10.)

27 E-stability pertains to the convergence of meta-time iterations that may or may not drive non-RE expectations functions to their RE values. Evans and Honkapohja $(1999,2001)$ show that in the cases at hand E-stability implies convergence of a real-time least-squares learning process like that of Marcet and Sargent (1989). For a useful introduction, see Bullard and Mitra (2000). 


\section{Figure 3}
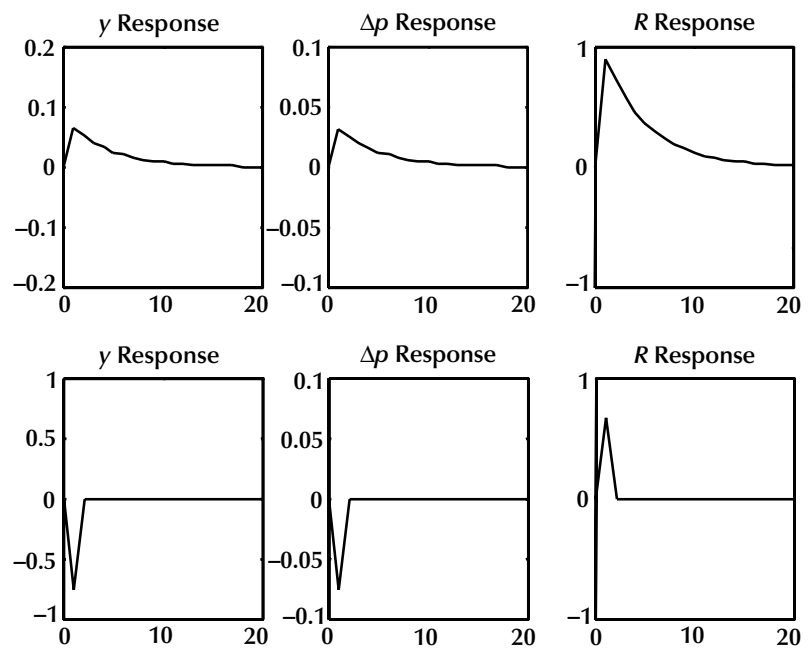

NOTE: Responses to unit shocks to IS (top) and policy rule (bottom) with $\mu_{1}=53.0$.
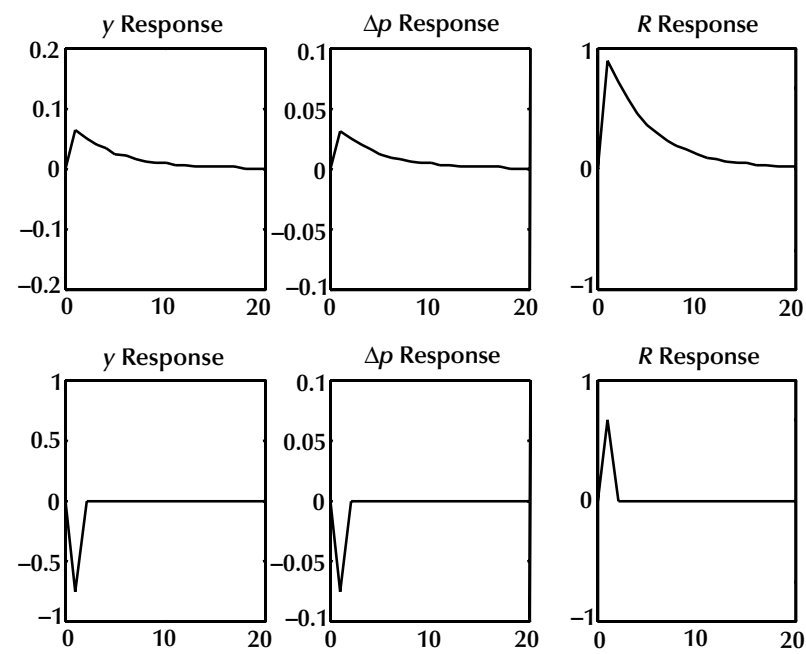

NOTE: Responses to unit shocks to IS (top) and policy rule (bottom) with $\mu_{1}=53.1$.

Evans and Honkapohja (1999, pp. 487-506; 2001, Chap. 10). These results indicate that their method of determining an expectation function would lead to the MSV solution in the case at hand.

The second line of argument to be developed here is to emphasize (i) that the unique MSV solution is available in the high $\mu_{1}$ cases pointed to by the Woodford warning and (ii) that this solution is well behaved in the sense of experiencing no discontinuity when passing through the critical values that delineate the region of multiple stable solutions. Specifically, impulse response functions for the MSV solution are virtually indistinguishable for $\mu_{1}$ values just above and just below the $\mu_{1}^{c}$ critical value at which solution multiplicity sets in. By contrast, the non-MSV solutions are highly different for the same pairs of $\mu_{1}$ values (i.e., just above and just below $\left.\mu_{1}^{c}\right) .28$

To illustrate this, let us take a numerical example in which $b_{1}=-0.75, \beta=0.99, \alpha=0.1$, and $\rho_{1}=0.8$. In this case the critical value of $\mu_{1}$ will be

$$
\begin{aligned}
& \mu_{1}^{c}=\left[2\left(0.99^{0.5}\right)+1.99\right] /(0.75)(0.1)= \\
& {[1.99+1.99] / 0.75=53.07 .}
\end{aligned}
$$

For values of $\mu_{1}$ less than 53.07 , there will be a single stable solution; for values above 53.07 there will be multiple stable solutions. ${ }^{29}$ But for values of $\mu_{1}$ close to 53.07, the behavior of the MSV solution will be virtually identical regardless of whether $\mu_{1}$ is slightly below, equal to, or slightly above 53.07. This is demonstrated in Figure 3, where impulse response functions for $y, \Delta p$, and $R$ are shown for unit shocks to the IS function (i.e., $v_{t}=1.0$ ) and the policy rule (i.e., $e_{t}=1.0$ ). The plots with $\mu_{1}=53.0$ and $\mu_{1}=53.1$ are, it seems fair to say, virtually indistinguishable.

More generally, properties of the MSV impulse response functions change continuously with values of $\mu_{1}$. This is illustrated in Figures 4 and 5. In the former, we have cases with $\mu_{1}=10$ and $\mu_{1}=20$, both of which imply unique stable solutions. The response peaks in $y$ and $\Delta p$ are reduced smoothly in size as $\mu_{1}$ increases from 10 to 20 to 53 . Then these reductions continue to obtain, in a smooth manner, as $\mu_{1}$ is increased further to 80 and 200; see Figure 5.

Behavior of the non-MSV solution contrasts sharply, and is distinctly non-continuous. For $0<\mu_{1}<53.07$, roots to (44) are complex so (38) gives the only solution. Then with $\mu_{1}=53.1$, we obtain a stable non-MSV solution (in addition to the stable MSV solution) as shown in the top panel of Figure $6 .{ }^{30}$ Since the responses to $e_{t}$ involve coefficients in which the denominator equals the $\operatorname{AR}(1)$

\footnotetext{
28 I am indebted to Doug Laxton for suggesting comparisons based on impulse response functions.

29 This is verified by Matlab calculation of solutions using my modification of Klein's (2000) QZ algorithm.

30 These non-MSV solutions are obtained by adding to the Matlab file mentioned previously a subroutine written by Christopher Sims, qzswitch.m, to generate the solution implied by a different ordering of the system's generalized eigenvalues, in the manner mentioned on p. 633 of McCallum (1999).
} 


\section{Figure 4}
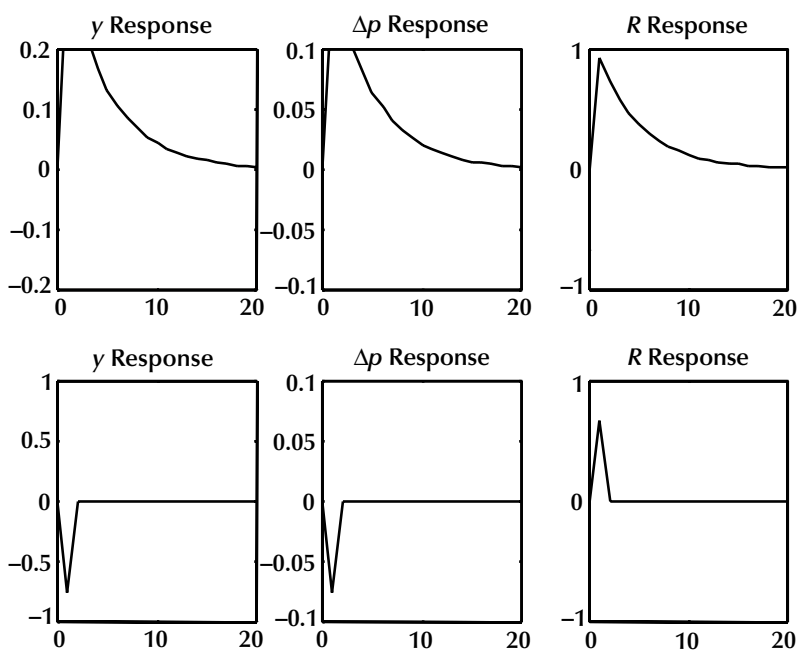

NOTE: Responses to unit shocks to IS (top) and policy rule (bottom) with $\mu_{1}=10.0$.
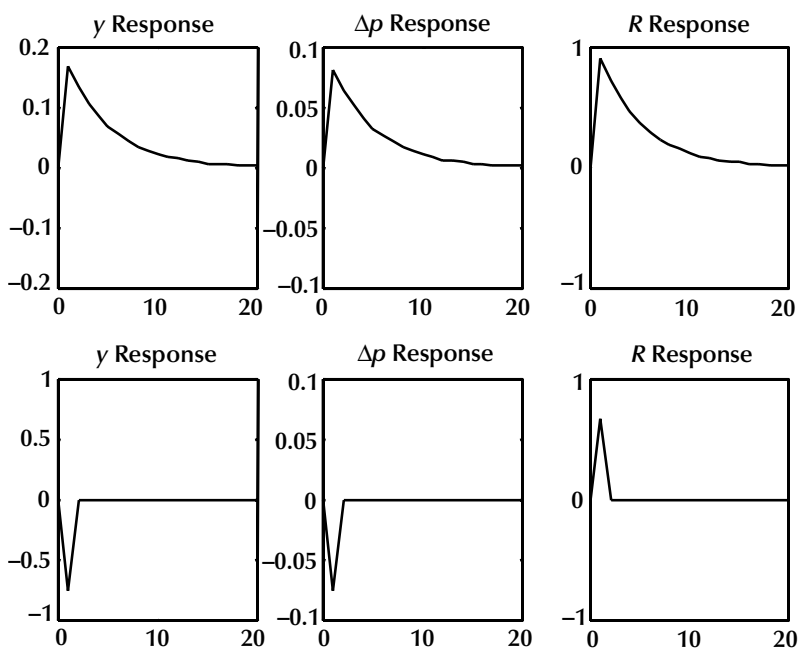

NOTE: Responses to unit shocks to IS (top) and policy rule (bottom) with $\mu_{1}=20.0$.

parameter for the $e_{t}$ process, these responses are "infinite" when $e_{t}$ is white noise. Consequently, a value of 0.01 is used for this $\operatorname{AR}(1)$ parameter in the model for Figure 6. A comparison with Figure 3 shows, not surprisingly, that this non-MSV solution is not at all similar to the MSV solution with $\mu_{1}=$ 53.0. Next, consider the bottom panel of Figure 6 , where $\mu_{1}=80$. It can be seen that the increase in $\mu_{1}$ decreases the responsiveness of $R_{t}$ and leaves larger peaks for $y_{t}$ and $\Delta p_{t}$ in response to both shocks. Also note that $y_{t}$ and $\Delta p_{t}$ blip upward in response to a surprise increase in $R_{t}$ and that the responses of

\section{Figure 5}
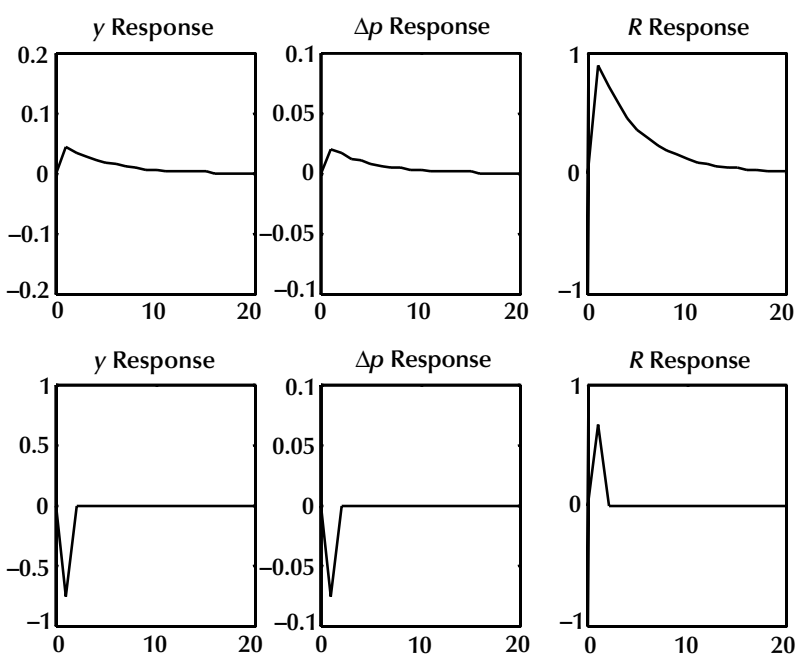

NOTE: Responses to unit shocks to IS (top) and policy rule (bottom) with $\mu_{1}=\mathbf{8 0 . 0}$.
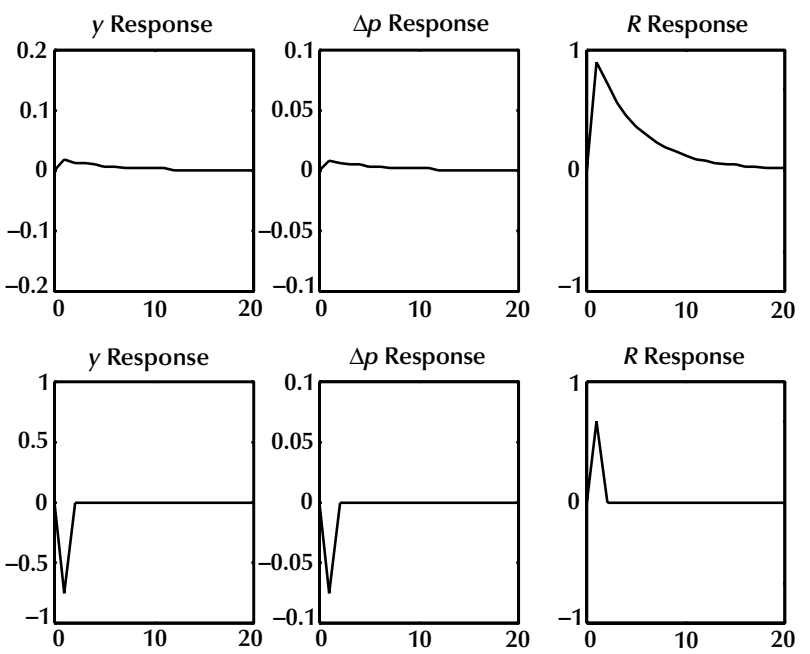

NOTE: Responses to unit shocks to IS (top) and policy rule (bottom) with $\mu_{1}=\mathbf{2 0 0 . 0 .}$

$y_{t}$ and $R_{t}$ are huge. Finally, if we let the autoregressive parameter generating $e_{t}$ be 0.04 instead of 0.01 , the direction of the $y_{t}$ and $\Delta p_{t}$ responses to $e_{t}$ flips over to become negative. (This case is not shown.)

These results illustrate, for one representative set of parameter values, the well-behaved nature of the MSV solution and the erratic nature of the nonMSV (bubble) solutions. Such results also obtain for other parameter values and clearly suggest the desirability of considering the MSV solutions as the sole economically relevant solution. If this strategy is adopted, i.e., if the MSV solution is taken to rep- 


\section{Figure 6}
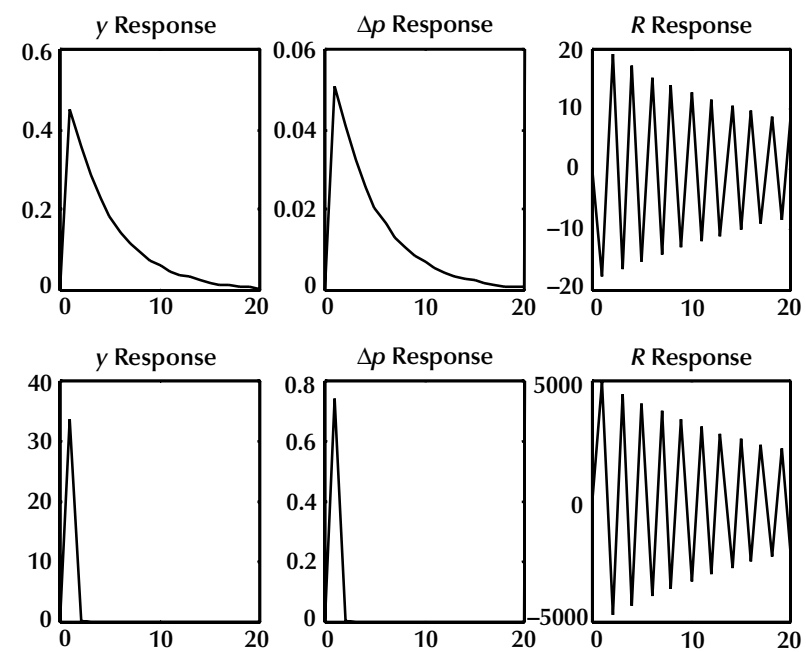

NOTE: Non-MSV solution; unit shocks to IS (top) and policy rule (bottom) with $\mu_{1}=53.1$.
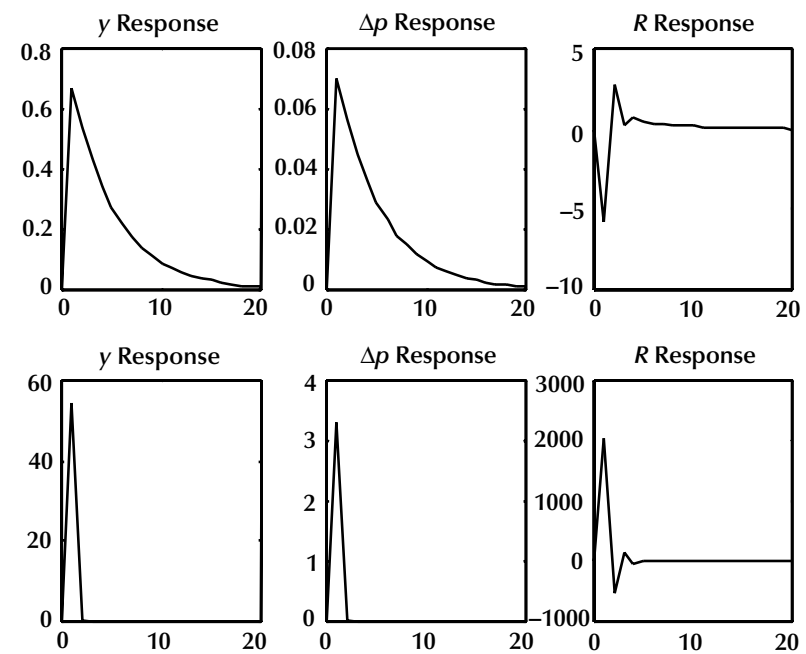

NOTE: Non-MSV solution; unit shocks to IS (top) and policy rule (bottom) with $\mu_{1}=\mathbf{8 0 . 0}$.

resent implied behavior for the model at hand, then there is no compelling reason to believe that large $\mu_{1}$ values will generate undesirable behavior. In that case, preemptive inflation forecast targeting with an $R_{t}$ instrument will not be subject to the dangers mentioned above.

\section{ON THE VALIDITY OF THE TAYLOR PRINCIPLE}

As a related matter, let us now consider the consequences of having a policy rule that fails to satisfy the Taylor principle, i.e., that an interest rate policy rule should respond by more than point-forpoint to inflation or its expectation. Both Taylor (1999) and Clarida, Gali, and Gertler (1999) emphasize that this requirement, which translates into $\mu_{1}>0$ in our model (32) through (34), implies that the real rate of interest will be moved upward (tightening policy) when inflation exceeds its target (and vice versa). Our analysis of the previous section was principally concerned with cases in which $\mu_{1}>\mu^{c}$, but it was shown using (44) that solution multiplicity also obtains when $\mu_{1}<0$. Thus it might be thought that our argument for downplaying the importance of solution multiplicity would also apply to cases with $\mu_{1}<0$, thereby contradicting the Taylor principle. Such is not the case, however, and it is the task of this section to explain why. In other words, we will determine what is the true problem posed, from the MSV perspective, by $\mu_{1}<0$.

For our argument to be different for "indeterminacies" with $\mu_{1}<0$, as compared with those with $\mu_{1}>\mu^{c}$, it must not be the existence of solution multiplicities per se that is considered problematic when $\mu_{1}<0$. Instead, there must be some other condition that prevails when $\mu_{1}<0$ and represents a problem that is, according to the present argument, of genuine importance.

Once again this problem is the absence of E-stability. Bullard and Mitra (2000) show that $\mu_{1}<0$ implies the absence of E-stability, and therefore the failure of least-squares learning, for separate cases in which $\pi_{t}, \pi_{t-1}$, and $E_{t-1} \pi_{t+j}$ enter the policy rule. ${ }^{31}$ This can be seen by inspection of their Figures 1 through 3. Since E-stability of an MSV solution enhances the attractiveness of that solution by indicating that it may be of empirical relevance, its absence for $\mu_{1}<0$ suggests that policy rules with $\mu_{1}<0$ should be avoided.

An interesting application of this argument concerns the special case in which $\mu_{1}=-1$ with $\Delta p_{t}$ in the rule and $\mu_{2}=0$, i.e., the case of a pure interest rate peg: $R_{t}=$ constant. Then the Bullard-Mitra results imply that E-stability does not prevail. This constitutes a version, with an optimizing model, of the argument of Howitt (1992). Note that it applies to a maintained interest rate peg, not to the use of an interest rate instrument.

An alternative argument for the case with $-1<\mu_{1}<0$ can be developed as follows. Consider a model in which the endogenous variable $x_{t}$ is generated by the relationship

\footnotetext{
${ }^{31}$ Here I am discussing cases with $\mu_{2}=0$. Bullard and Mitra's results are more general, since they also consider $\mu_{2}>0$.
} 


$$
x_{t}=a_{0}+a_{1} E_{t} x_{t+1}+a_{2} x_{t-1}+z_{t},
$$

where $z_{t}$ is a stationary exogenous forcing variable with an unconditional mean of zero. Now apply the unconditional expectation operator to get

$$
E x_{t}=a_{0}+a_{1} E x_{t+1}+a_{2} E x_{t-1}+0 \text {. }
$$

Assuming stationarity, we then have

$$
E x_{t}=a_{0} /\left(1-a_{1}-a_{2}\right) \text {. }
$$

Clearly, as $a_{1}+a_{2}$ approaches 1.0 from below, the unconditional mean of $x_{t}$ approaches $+\infty$, whereas if $a_{1}+a_{2}$ approaches 1.0 from above, then the mean of $x_{t}$ approaches $-\infty$. Thus there is an infinite discontinuity at $a_{1}+a_{2}=1$. So to be well formulated, the model needs to include a parameter restriction that rules out $a_{1}+a_{2}=1$. From a purely mathematical perspective, $a_{1}+a_{2}>1$ would do as well, but for economic plausibility the preferred restriction is $a_{1}+a_{2}<1$. Note that if $a_{2}=0$, this amounts to $1-a_{1}>0$.

To see the relevance of the foregoing for the model (32) through (34), with $\mu_{2}=0$, write the system as

$$
\left[\begin{array}{cc}
1 & 0 \\
-\alpha & 1
\end{array}\right]\left[\begin{array}{c}
y_{t} \\
\Delta p_{t}
\end{array}\right]=\left[\begin{array}{cc}
1 & b_{1} \mu_{1} \\
0 & \beta
\end{array}\right] E_{t}\left[\begin{array}{c}
y_{t+1} \\
\Delta p_{t+1}
\end{array}\right]+\left[\begin{array}{ll}
1 & 0 \\
0 & 1
\end{array}\right]\left[\begin{array}{c}
v_{t} \\
e_{t}
\end{array}\right]
$$

or

$$
x_{t}=A E_{t} x_{t+1}+C z_{t},
$$

where $x_{t}=\left[y_{t} \Delta p_{t}\right]^{\prime}, z_{t}=\left[v_{t} e_{t}\right]^{\prime}$, and

$$
A=\left[\begin{array}{cc}
1 & 0 \\
-\alpha & 1
\end{array}\right]^{-1}\left[\begin{array}{cc}
1 & b_{1} \mu_{1} \\
0 & \beta
\end{array}\right]=\left[\begin{array}{cc}
1 & b_{1} \mu_{1} \\
\alpha & \alpha b_{1} \mu_{1}+\beta
\end{array}\right]
$$

Now the counterpart of $1-a_{1}>0$ in the previous example is that $\operatorname{det}(I-A)>0$. If that condition does not hold, the model is not well formulated and the unconditional mean of $x_{t}$ passes through an infinite discontinuity. But the value of $\operatorname{det}(I-A)$ in the case at hand is $-\alpha b_{1} \mu_{1}$. Thus with $\alpha>0$ and $b_{1}<0$, the requirement for this model to be well formulated is $\mu_{1}>0$. This follows the original development and promotion of the MSV solution, in which McCallum (1983, p. 160) points out "the desirability of specifying admissible parameter values as an integral part of the model."

The main conclusion of this section is that the Taylor principle is basically correct. If $\mu_{2}$ is positive, then $\mu_{1}$ can be negative to some extent without losing E-stability; according to Bullard and Mitra (2000), the necessary and sufficient condition for E-stability is $\alpha \mu_{1}+(1-\beta) \mu_{2}>0$. But that is a modification, not a fundamental contradiction, of the principle. Its basic logic is sound.

\section{CONCLUDING REMARKS}

In the foregoing sections the following arguments have been developed: (i) models without monetary aggregates do not imply that inflation is a non-monetary phenomenon and are not necessarily non-monetary models; (ii) theoretical considerations suggest that such models are misspecified, but the quantitative significance of this misspecification seems to be very small; (iii) arguments based on "indeterminacy" findings, e.g., regarding policy rules that respond strongly to expected future inflation rates, are of dubious merit: there are various reasons for believing that findings of solution multiplicity are theoretical curiosities that have little or no real world significance; (iv) monetary policy rules that violate the Taylor principle, by contrast, possess another characteristic - the absence of E-stability and least-squares learnability - that suggests undesirable behavior in practice.

These points are mostly supportive of the notion that policy analysis in models without money, based on interest rate policy rules, is not fundamentally misguided. It is important, consequently, to mention explicitly that they do not imply that policy rules with an interest rate instrument are necessarily preferable to ones based on a controllable monetary aggregate, such as total reserves or the monetary base. My own preference has been, for many years, for base instrument rules. Furthermore, my recent (2000b) study of the counterfactual historical performance of alternative rules for the United States, the United Kingdom, and Japan suggests that-for reasons that are not entirely clear-base instrument rules would have provided better policy guides than interest instrument rules over 1965-98. But the topics considered in the present paper are ones of considerable fundamental interest, and it is important in choosing among different types of rules-i.e., different ways of conducting policythat central bankers not be misled by dubious economic analysis. ${ }^{32}$

\footnotetext{
32 In that regard, the analysis in the fourth section of the paper ("Are Rational-Expectation Indeterminacies Important?") also suggests that some results used to argue in favor of an interest rate instrument, rather than the monetary base—see, e.g., Woodford (1999) — are also dubious.
} 


\section{REFERENCES}

Archer, David J. “Inflation Targeting in New Zealand.” Paper presented at the International Monetary Fund Institute Seminar on Inflation Targeting, 20-21 March 2000.

Bernanke, Ben S. and Woodford, Michael. "Inflation Forecasts and Monetary Policy." Journal of Money, Credit and Banking, November 1997, 29(4), pp. 653-84.

Bullard, James and Mitra, Kaushik. "Learning About Monetary Policy Rules.” Working Paper 2000-001B, Federal Reserve Bank of St. Louis, July 2000.

Carlstrom, Charles T. and Fuerst, Timothy S. "ForwardLooking Versus Backward-Looking Taylor Rules.” Working Paper, April 2000.

Casares, Miguel and McCallum, Bennett T. "An Optimizing IS-LM Framework with Endogenous Investment.” Working Paper, September 2000.

Christiano, Lawrence J. and Gust, Christopher J. "Comment" in Taylor (1999), pp. 299-316.

Clarida, Richard; Gali, Jordi and Gertler, Mark. "The Science of Monetary Policy: A New Keynesian Perspective." Journal of Economic Literature, December 1999, 37(4), pp. 1661-707.

and "Monetary

Policy Rules and Macroeconomic Stability: Evidence and Some Theory." Working Paper 6442, National Bureau of Economic Research, March 1998.

Estrella, Arturo and Fuhrer, Jeffrey C. "Dynamic Inconsistencies: Counterfactual Implications of a Class of Rational Expectations Models.” Working Paper, July 2000.

Evans, George W. "Selection Criteria for Models with NonUniqueness.” Journal of Monetary Economics, September 1986, 18(2), pp. 147-57.

and Honkapohja, Seppo. "Learning Dynamics," in John B. Taylor and Michael Woodford, eds., Handbook of Macroeconomics, Volume 1A. New York: NorthHolland, 1999, pp.449-542.

and Learning and Expectations in Macroeconomics. Princeton, NJ: Princeton University Press, 2001.

Freedman, Charles. "The Canadian Experience with
Targets for Reducing and Controlling Inflation.” Paper presented at the International Monetary Fund Institute Seminar on Inflation Targeting, 20-21 March 2000.

Friedman, Benjamin M. "The Future of Monetary Policy: The Central Bank as an Army with Only a Signal Corps?" International Finance, November 1999, 2(3), pp. 321-38.

Gail, Jordi and Gertler, Mark. "Inflation Dynamics: A Structural Econometric Analysis.” Journal of Monetary Economics, October 1999, 44(2), pp. 195-222.

Goodfriend, Marvin. "Monetary Policy Comes of Age: A 20th Century Odyssey." Federal Reserve Bank of Richmond Economic Quarterly, Winter 1997, 83(1), pp. 1-22.

Goodhart, Charles. "Can Central Banking Survive the IT Revolution?” International Finance, July 2000, 3(2), pp. 189-209.

Gurley, John G. and Shaw, Edward S. Money in a Theory of Finance. Washington, DC: The Brookings Institution, 1960.

Howitt, Peter. "Interest Rate Control and Nonconvergence to Rational Expectations." Journal of Political Economy, August 1992, 100(4), pp. 776-800.

Ireland, Peter N. "Money's Role in the Monetary Business Cycle." Working Paper 8115, National Bureau of Economic Research, February 2001.

Isard, Peter; Laxton, Douglas and Eliasson, Ann-Charlotte. "Simple Monetary Policy Rules Under Model Uncertainty." International Tax and Public Finance, November 1999, 6(4), pp. 537-77. Also in P. Isard, A. Razin, and A.K. Rose, eds., International Finance and Financial Crises: Essays in Honour of Robert P. Flood, Jr. New York: Kluwer Academic Publishers, 2000.

Johnson, Harry G. "Monetary Theory and Policy." American Economic Review, June 1962, 52(3), pp. 335-84.

Kerr, William and King, Robert G. "Limits on Interest Rate Rules in the IS Model." Federal Reserve Bank of Richmond Economic Quarterly, Spring 1996, 82(2), pp. 47-77.

King, Mervyn A. "The Monetary Policy Committee Two Years On.” Bank of England Quarterly Bulletin, August 1999, 39, pp. 297-303.

Klein, Paul. "Using the Generalized Schur Form to Solve a 
Multivariate Linear Rational Expectations Model." Journal of Economic Dynamics and Control, September 2000, 24(10), pp. 1405-23.

Lange, Oscar. "Say's Law: A Restatement and Criticism," in O. Lange, F. McIntyre, and T.O. Yntema, eds., Studies in Mathematical Economics and Econometrics. Chicago: 1942.

Lucas, Robert E., Jr. "Econometric Testing of the Natural Rate Hypothesis," in O. Eckstein, ed., Econometrics of Price Determination. Washington, DC: Board of Governors of the Federal Reserve System, 1972.

Marcet, Albert and Sargent, Thomas J. "Convergence of Least Squares Learning Mechanisms in Self-Referential Linear Stochastic Models." Journal of Economic Theory, April 1989, 4(2), pp. 337-68.

McCallum, Bennett T. "Price Level Determinacy with an Interest Rate Policy Rule and Rational Expectations.” Journal of Monetary Economics, November 1981, 8(3), pp. 319-29.

"On Non-Uniqueness in Rational Expectations Models: An Attempt at Perspective." Journal of Monetary Economics, March 1983, 11(2), pp. 139-68.

"Some Issues Concerning Interest Rate Pegging, Price Level Determinacy and the Real Bills Doctrine." Journal of Monetary Economics, January 1986, 17 , pp. $135-50$.

"Role of the Minimal State Variable Criterion in Rational Expectations Models." International Tax and Public Finance, November 1999, 6, pp. 621-39. Also in P. Isard, A. Razin, and A.K. Rose, eds., International Finance and Financial Crises: Essays in Honor of Robert P. Flood, Jr. New York: Kluwer Academic Publishers, 2000.

"Theoretical Analysis Regarding a Zero Lower Bound on Nominal Interest Rates." Journal of Money, Credit and Banking, November 2000a, 32(4), pp. 870-94.

"Alternative Monetary Policy Rules: A Comparison with Historical Settings for the United States, the United Kingdom, and Japan." Federal Reserve Bank of Richmond Economic Quarterly, Winter 2000b, 86(4), pp. 49-79.

and Nelson, Edward. "Performance of Operational Policy Rules in an Estimated Semiclassical Structural Model," in Taylor (1999), pp. 15-45. and "An Optimizing IS-LM Specification for Monetary Policy and Business Cycle Analysis," Journal of Money, Credit and Banking, August 1999b, 31(3, Part 1), pp. 296-316.

Meltzer, Allan H. "Commentary: Monetary Policy at Zero Inflation," in New Challenges for Monetary Policy. Federal Reserve Bank of Kansas City, 1999, pp. 261-76.

Nelson, Edward. "Direct Effects of Base Money on Aggregate Demand.” Working Paper, May 2000.

Olivera, Julio H. "On Passive Money.” Journal of Political Economy, July/August 1970, 78(4, Part 2), pp. 805-14.

Parkin, Michael. "A Comparison of Alternative Techniques of Monetary Control Under Rational Expectations." Manchester School, September 1978, 46(3), pp. 252-87.

Patinkin, Don. "The Indeterminacy of Absolute Prices in Classical Economic Theory." Econometrica, January 1949, 17(1), pp. 1-27

"Financial Intermediaries and the Logical Structure of Monetary Theory: A Review Article." American Economic Review, March 1961, 51(1), pp. 95-116.

Money, Interest, and Prices. 2nd Ed. New York: Harper and Row, 1965.

Rotemberg, Julio J. and Woodford, Michael. "An Optimization-Based Econometric Framework for the Evaluation of Monetary Policy," in B.S. Bernanke and J.J. Rotemberg, eds., NBER Macroeconomics Annual, 1997. Cambridge, MA: MIT Press, 1997.

Sargent, Thomas J. Macroeconomic Theory. New York: Academic Press, 1979. and Wallace, Neil. "'Rational' Expectations, the Optimal Monetary Instrument, and the Optimal Money Supply Rule.” Journal of Political Economy, April 1975, 83(2), pp. 241-54.

Svensson, Lars E.O. "Inflation Forecast Targeting: Implementing and Monitoring Inflation Targets." European Economic Review, June 1997, 41(6), pp. 1111-46.

Taylor, John B. "Discretion Versus Policy Rules in Practice." Carnegie-Rochester Conference Series on Public Policy, December 1993, 39, pp. 195-214. 


\section{RE VIE W}

ed. Monetary Policy Rules. Chicago: University of Chicago Press for NBER, 1999.

Woodford, Michael. "Nonstandard Indicators for Monetary Policy: Can Their Usefulness Be Judged From Forecasting Regressions?" in G.N. Mankiw, ed., Monetary Policy.

Chicago: University of Chicago Press for NBER, 1994, pp. 99-115.

"Price-Level Determinacy Without Control of a Monetary Aggregate." Carnegie-Rochester Conference Series on Public Policy, December 1995, 43, pp. 1-46.

"Price Level Determination Under Interest Rate Rules" in Interest and Prices. Unpublished manuscript, 1999, Chap. 2. 